\title{
Tuberculosis mortality and associated factors at King Abdulaziz Medical City Hospital
}

\author{
Rawabi Aljadani ${ }^{1 *}$ (D), Anwar E. Ahmed ${ }^{2,3,4}$ and Hamdan AL-Jahdalii 2,34
}

\begin{abstract}
Background: Tuberculosis (TB) continues to be a public health challenge in Saudi Arabia, particularly for the elderly. This study was conducted to estimate mortality per 1000 person-year among TB and resistant TB cases and to identifying factors associated with mortality.

Methods: This is a retrospective cohort study of 713 new TB cases at King Abdulaziz Medical City in Riyadh diagnosed between January 1, 2000, and December 31, 2016. Patient medical records and microbiology lab databases were used to identify TB cases. Through reviews were conducted of patients' medical records, including physician notes, physical examinations, radiology (scans and imaging), laboratory tests, and follow-up notes. Collected data include demographic information, clinical features, diagnoses, comorbidities, and death rates.

Results: Of the 713 TB patients included in this study, 110 died, giving an average mortality rate of 22 per 1000 personyears (PY; 95\% Cl: 18.2-26.4). Elderly patients ( $\geq 60$ years) had a higher mortality rate of 36.5 per 1000 PY (95\% Cl: 28.9-45.5). As age increases by one year, the hazard of mortality increase by $2.4 \%$ (aHR: 1.024 [95\% Cl: 1.009-1.039, $P=0.002]$ ). Higher hazard of mortality was found among males (aHR: 2.014 [95\% Cl: 1.186-3.418, $P=0.010]$ ]. Patients with respiratory and other types of comorbidities and cancer had a higher mortality hazard (aHR: 1.898 [95\% Cl: 1.005-3.582, $P=0.048]$; aHR: 2.346 [95\% Cl: 1.313-4.192, $P=0.004$ ]; aHR: 3.292 [95\% Cl: 1.804-6.006, $P=0.001]$ ), respectively. Multidrug-resistant TB (MDR-TB) was found in 2 cases (0.28\%) (95\% Cl: $0.08-1.02)$, 1.68\% were resistant to only one antibiotic, $0.14 \%$ had rifampicine-resistant TB (RR-TB), $0.28 \%$ had MDR-TB, and $0.14 \%$ had extensively drug-resistant TB (XDR-TB).

Conclusions: The mortality rate among TB patients was found to be 22 per 1000 person-year at our center. TB was associated with high mortality rates among males, the elderly, and patients with cancer, respiratory illness, and other comorbidities. Future clinical practice should include establishing an efficient TB diagnostic program and continued hazard assessment of TB treatment options.
\end{abstract}

Keywords: Tuberculosis, Mortality, Multidrug-resistant

\section{Highlights}

- This is the first study to assess mortality rate per person-years (PY) among tuberculosis patients in Saudi Arabia. The overall mortality rate among Saudi resident patients with tuberculosis was 22 per 1000 PY.

- Future clinical practice should include the hazard assessment in tuberculosis patients' treatment plans and consider closer monitoring of cases

\footnotetext{
* Correspondence: raar_66@hotmail.com; aljadanira@gmail.com

'Saudi Food and Drug Authority, Riyadh, Saudi Arabia

Full list of author information is available at the end of the article
}

with higher rates of mortality. In this study, higher risk of death with tuberculosis was observed among males, the elderly, cancer patients, and patients with pulmonary disease or other comorbidities.

\section{Background \\ Infectious diseases are one of the most significant public health challenges in Saudi Arabia. The concern over such diseases has played a significant role in es- tablishing research funding priorities for pivotal insti- tutions, such as King Abdullah International Medical}

(c) The Author(s). 2019 Open Access This article is distributed under the terms of the Creative Commons Attribution 4.0 International License (http://creativecommons.org/licenses/by/4.0/), which permits unrestricted use, distribution, and 
Research Center, King Abdulaziz City for Science and Technology (KACST) and King Abdullah University of Science and Technology. One of these diseases is Tuberculosis (TB) which continues to be a public health concern in Saudi Arabia, particularly endangers the elderly [1]. TB mortality among Saudis was investigated from 2001 to 2010 , a $6.4 \%$ fatality rate was reported, higher fatality rate was found among males and elderly [2]. Mortality from TB increases with TB resistance. TB bacteria may develop resistance to the two most powerful drugs (rifampicin and isoniazid) prescribed to treat the disease $[3,4]$. This conundrum is referred to as multidrug-resistant TB (MDR-TB). In some situations, TB bacteria may develop even more severe resistance to several powerful drugs $[3,4]$, and this is referred to as extensively drug-resistant $\mathrm{TB}$ (XDR-TB). Both MDR-TB and XDR-TB are dangerous medical conditions that can affect patient outcomes, particularly mortality and TB control [5-11]. Further, TB has economic and social impacts. Economically, TB treatment ranges from $\$ 276$ to $\$ 1546$ USD per person for the complete treatment course. Cost estimates for MDR-TB treatment range from $\$ 1000$ to $\$ 10,000$ USD [12]. Additionally, treatment complications and hospitalization may increase indirect costs. Socially, TB affects all quality of life domains, including general health perceptions, psychological health, well-being, and social functioning [13]. The World Health Organization (WHO; 2015) recently reported an estimated 580,000 cases of MDR/rifampicin-resistant TB (MDR/RR-TB), with MDR-TB accounting for 83\% [11]. In 2015, there were about 250,000 deaths from MDR/RR-TB, worldwide [11]. Concerning Saudi Arabia, WHO has reported an annual estimate of 150 (range, 120-180) cases with a rate of 0.48 per 100,000 of MDR/RR-TB [14]. Many studies have investigated the prevalence of TB in Saudi Arabia. A retrospective review of microbiology and infection control databases at King Faisal Specialist Hospital and Research Centre reported an overall anti-TB drug resistance rate of $2.5 \%$ in $764 \mathrm{~TB}$ isolates [15]. A nationwide study from seven regions of Saudi Arabia reported a rate of 4.5\% in 1505 clinical isolates of TB [16]. A study in a Saudi tertiary care unit on 289 isolates reported at least one anti-TB drug (8.7\%) [17]. Another study reported an MDR-TB rate of $1.4 \%$ in a sample of antibiotic susceptibility of 1681 non-repetitive TB isolates [18]. Nonetheless, mortality and risk factors associated with TB and MDR TB are not well studied in Saudi Arabia, none of the previous studies assessed TB mortality rate per person-years (PY) among the Saudi population. In this study, we aim to explore the mortality rate per person-years (PY) of TB and resistant TB patients and identify the potential risk factors associated with higher mortality, which is crucial in TB control and treatment outcome improvements.

\section{Methods}

This is a retrospective cohort study of new TB cases at King Abdulaziz Medical City Hospital between January 1, 2000, and December 31, 2016. A list of all registered confirmed or suspected TB patients during the prespecified timeframe was obtained from the medical records and microbiology lab databases. Next, full medical records for all of the patients were thoroughly reviewed (including physician notes, physical examinations, radiology (scans and imaging), laboratory tests, and follow-up notes), and newly diagnosed TB cases during the study timeframe were identified. For the last 16 years, King Abdul Aziz Medical City stored all patients' medical history in paper-based health documents. TB was diagnosed according to the American Thoracic Society/Infectious Diseases Society of America/Centers for Disease Control and Prevention Clinical Practice Guidelines [19]. Pulmonary TB (PTB) was diagnosed based on the symptoms, chest $\mathrm{X}$-rays, and laboratory testing results of either a three acid-fast bacilli (AFB) smear and/or QuantiFERON-TB Gold test. Extra pulmonary TB (EPTB) was diagnosed based on symptoms, radiological scans results, and the results of suspected location biopsy or aspirate culture. Positive specimens were tested for drug susceptibility for rifampicin, isoniazid, ethambutol, and streptomycin to identify resistant cases. Both sexes and all age groups were eligible for inclusion.

Data were collected from the medical records using a structured data collection form. Demographic data included age, gender, nationality, smoking status, and body mass index (BMI). Clinical data included general (diarrhea, nausea, vomiting), systemic (fever, headache, chest pain), respiratory (cough, hemoptysis, shortness of breath), and lung cavitations. We also recorded the following patient diagnosis and comorbidity data: TB status, TB site, drug resistance, respiratory comorbidities (pulmonary disease, asthma, chronic obstructive pulmonary disease), other comorbidities (diabetes, hypertension, heart disease, hyperlipidemia, liver disease, renal disease), cancer, immunosuppression due to infection, genetic condition, and medication. In addition, we collected the following data about death: date of death, date of TB diagnosis, and date of loss to follow up (date of last follow-up visit to the clinic). TB was considered the cause of death in all patients who died while under anti-TB treatment, regardless of the primary cause of death. Person-years (PY) of cohort members started when anti-TB treatment was initiated and ended on the date of death, date of loss to follow up, or December 31, 2016, whichever came first. This research was funded by KACST Grant Programs for Universities and Research Centers (GPURC).

\section{Statistical analysis}

Descriptive statistics were used to summarize patient characteristics; Frequencies and percentages (n, \%) were 
computed to describe and summarize categorical variables. We calculated mortality rates per $1000 \mathrm{PY}$ and 95\% CIs. The Cox proportional hazards $(\mathrm{CPH})$ model was used to identify risk factors associated with shorter survival among TB cases. In all analyses, $P<0.05$ was considered significant. Databases were analyzed using SPSS version 23 [20].

\section{Results}

In this study, 713 patients were diagnosed with $\mathrm{TB}$ at King Abdulaziz Medical City Hospital between January 1, 2000, and December 31, 2016. The majority were male (58.80\%), Saudi (93.7\%), and aged 30 years or older. Of the patients, $13.7 \%$ were obese, and 53.6 and $55.4 \%$ complained of respiratory and systemic symptoms, respectively. Of the sample, 9.7\% had respiratory comorbidities, $6.6 \%$ had cancer, and $49.9 \%$ had pulmonary TB. Other characteristics are mentioned in Table 1.

In our study, 19 (2.66\%; 95\% CI: 1.71-4.12) had resistant TB, and MDR-TB was found in 2 cases $(0.28 \%$; 95\% CI: 0.08-1.02). Additionally, $1.68 \%$ were resistant to only one antibiotic, $0.14 \%$ had RR-TB, $0.28 \%$ had

Table 1 Patient's characteristics

\begin{tabular}{|c|c|c|c|}
\hline Characteristics & Levels & $N$ & $\%$ \\
\hline \multirow[t]{4}{*}{ Age years (1-101) } & $\leq 14$ & 39 & 5.5 \\
\hline & $15-29$ & 114 & 16 \\
\hline & $30-59$ & 240 & 33 \\
\hline & $\geq 60$ & 320 & 44.9 \\
\hline \multirow[t]{2}{*}{ Gender } & Male & 419 & 58.8 \\
\hline & Female & 294 & 41.2 \\
\hline \multirow[t]{2}{*}{ Nationality } & Saudi & 668 & 93.7 \\
\hline & Non-Saudi & 45 & 6.3 \\
\hline \multirow[t]{4}{*}{ BMI kg/m² (11.12-53.41) } & $<18.5$ & 100 & 20.4 \\
\hline & $18.5-24.9$ & 202 & 41.3 \\
\hline & $25-29.9$ & 120 & 24.5 \\
\hline & $\geq 30$ (Obesity) & 67 & 13.7 \\
\hline Smoker & & 40 & 6.2 \\
\hline \multirow[t]{4}{*}{ Clinical features } & General & 85 & 11.9 \\
\hline & Systemic & 395 & 55.4 \\
\hline & Respiratory & 382 & 53.6 \\
\hline & Cavitations & 91 & 12.8 \\
\hline \multirow[t]{2}{*}{ Site of TB } & Pulmonary & 356 & 49.9 \\
\hline & Extra Pulmonary & 357 & 50.1 \\
\hline Resistant & & 19 & 2.7 \\
\hline \multirow[t]{4}{*}{ Comorbidities } & Respiratory & 69 & 9.7 \\
\hline & Other & 377 & 52.9 \\
\hline & Cancer & 47 & 6.6 \\
\hline & Immunocompromised & 47 & 6.6 \\
\hline
\end{tabular}

BM Body mass index
MDR-TB, and $0.14 \%$ had XDR-TB. Isoniazid and streptomycin had the highest resistance rates of 1.68 and 1.4\%, respectively. Antibiotics resistant cases are summarized in Table 2.

Mortality rates (per 1000 PY) are summarized in Table 3. Of the $713 \mathrm{~TB}$ patients included in this study, 110 died with an active TB, giving an average mortality rate of 22 per $1000 \mathrm{PY}$ (95\% CI: 18.2-26.4). Elderly patients 60 years old and above had a mortality rate of 36.5 per 1000 PY (95\% CI: 28.9-45.5), with survival probability stratified by age group, as illustrated in Fig. 1. Males had a mortality rate of 28.4 per 1000 PY (95\% CI: 22.5-35.3), with survival probability stratified by gender, as illustrated in Fig. 2. Mortality rate was the highest among PTB patients at 126.8 per 1000 PY (95\% CI: 97.2-162.8). Patients with respiratory comorbidities and patients with other comorbidities had mortality rates of 33.7 per 1000 PY (95\% CI: 20.27-52.83) and 31.7 per 1000 PY (95\% CI: 25.25-39.28), respectively. Cancer patients with TB had a mortality rate of 84.3 per $1000 \mathrm{PY}$ (95\% CI: 52.2-129.2).

The results of the univariate and multivariate $\mathrm{CPH}$ models are included in Table 4. The univariate $\mathrm{CPH}$ model shows that as age increased by one year, mortality hazard increased by $3.1 \%$ (HR: 1.031 [95\% CI: 1.021-1.042, $P=$ 0.001]). The hazard of mortality was $69.7 \%$ higher in males (HR: 1.697 [95\% CI: 1.132-2.542, $P=0.010]$ ). Patients with respiratory comorbidities had $82.3 \%$ higher hazard (HR: 1.823 [95\% CI: $1.087-3.057, P=0.023]$ ). Patients with other types of comorbidities has two times higher mortality hazard (HR: 2.377 [95\% CI: 1.569-3.602, $P=0.001]$ ). The hazard of mortality was three times higher in cancer patients (HR: 3.274 [95\% CI: 1.995-5.373, $P=0.001]$ ). According to the results of the multivariate $\mathrm{CPH}$ model, as age increased by one year, the hazard of mortality increased by $2.4 \%$ (aHR: 1.024 [95\% CI: 1.009-1.039, $P=0.002]$ ). The hazard of mortality was higher among males (aHR: 2.014 [95\% CI: $1.186-3.418, P=0.010])$. Patients who presented with general symptoms had 91.3\% higher hazard of mortality (aHR: 1.913 [95\% CI: 1.004-3.644, $P=0.049$ ]). Patients with respiratory comorbidities, other type of comorbidities, and cancer had higher mortality hazards

Table 2 Antibiotics resistant cases

\begin{tabular}{llll}
\hline Resistant cases & Antibiotic & $N$ & $\%$ \\
\hline Resistant to only one & Streptomycin & 6 & 0.84 \\
antibiotic & Isoniazid & 5 & 0.7 \\
& Rifampicin (RR-TB) & 1 & 0.14 \\
Resistant to two antibiotic & Isoniazid + Streptomycin & 3 & 0.42 \\
& Isoniazid + Ethambutol & 1 & 0.14 \\
& Isoniazid + Rifampicin (MDR-TB) & 2 & 0.28 \\
Resistant to all antibiotic & XDR-TB & 1 & 0.14 \\
\hline$R R-T B$ rifampicin-resistant tuberculosis, MDR-TB multidrug-resistant & & \\
tuberculosis, XDR-TB Extensively drug-resistant tuberculosis & &
\end{tabular}


Table 3 Mortality rates (per 1000 person-years (PY)) in NGHA (2000-2016)

\begin{tabular}{|c|c|c|c|c|c|c|}
\hline & \multirow[t]{2}{*}{ Level } & \multirow[t]{2}{*}{ Person-years } & \multirow[t]{2}{*}{ Deaths } & \multirow[t]{2}{*}{ Rate } & \multicolumn{2}{|c|}{$95 \% \mathrm{Cl}$} \\
\hline & & & & & Lower & Upper \\
\hline Overall & & 4990.97 & 110 & 22.0 & 18.2 & 26.4 \\
\hline \multirow[t]{4}{*}{ Age years } & $\leq 14$ & 275.06 & 3 & 10.9 & 2.7 & 29.6 \\
\hline & $15-29$ & 773.43 & 6 & 7.8 & 3.1 & 16.1 \\
\hline & $30-59$ & 1872.26 & 26 & 13.9 & 9.2 & 20 \\
\hline & $\geq 60$ & 2054.16 & 75 & 36.5 & 28.9 & 45.5 \\
\hline \multirow[t]{2}{*}{ Gender } & Male & 2676.86 & 76 & 28.4 & 22.5 & 35.3 \\
\hline & Female & 2314.11 & 34 & 14.7 & 10.3 & 20.3 \\
\hline \multirow[t]{2}{*}{ Nationality } & Saudi & 4760.43 & 102 & 21.4 & 17.5 & 25.9 \\
\hline & Non-Saudi & 230.54 & 8 & 34.7 & 16.1 & 65.9 \\
\hline \multirow[t]{2}{*}{ Obesity } & Yes & 2669.93 & 12 & 4.4 & 2.4 & 7.6 \\
\hline & No & 2321.04 & 67 & 28.9 & 22.5 & 36.4 \\
\hline \multirow[t]{2}{*}{ Smoke } & Smoker & 255.07 & 5 & 19.6 & 7.1 & 43.4 \\
\hline & Non-smoker & 4065.54 & 102 & 25.1 & 20.5 & 30.3 \\
\hline \multirow[t]{4}{*}{ Clinical features } & General & 507.54 & 18 & 35.5 & 21.6 & 54.9 \\
\hline & Systemic & 2941.69 & 56 & 19.0 & 14.52 & 24.54 \\
\hline & Respiratory & 2871.86 & 55 & 19.2 & 14.5 & 24.7 \\
\hline & Cavitations & 713.69 & 9 & 12.6 & 6.1 & 23.1 \\
\hline \multirow[t]{2}{*}{ Site of TB } & Pulmonary & 457.21 & 58 & 126.8 & 97.2 & 162.8 \\
\hline & Extra Pulmonary & 2807.25 & 52 & 18.5 & 13.9 & 24.1 \\
\hline \multirow[t]{2}{*}{ Resistant } & Yes & 135.8 & 1 & 7.4 & 0.3 & 36.3 \\
\hline & No & 4855.71 & 109 & 22.4 & 18.5 & 26.9 \\
\hline \multirow[t]{4}{*}{ Comorbidities } & Respiratory & 504.76 & 17 & 33.7 & 20.27 & 52.83 \\
\hline & Other & 2493.39 & 79 & 31.7 & 25.25 & 39.28 \\
\hline & Cancer & 225.43 & 19 & 84.3 & 52.2 & 129.2 \\
\hline & Immunocompromised & 344.73 & 8 & 23.2 & 10.7 & 44 \\
\hline
\end{tabular}

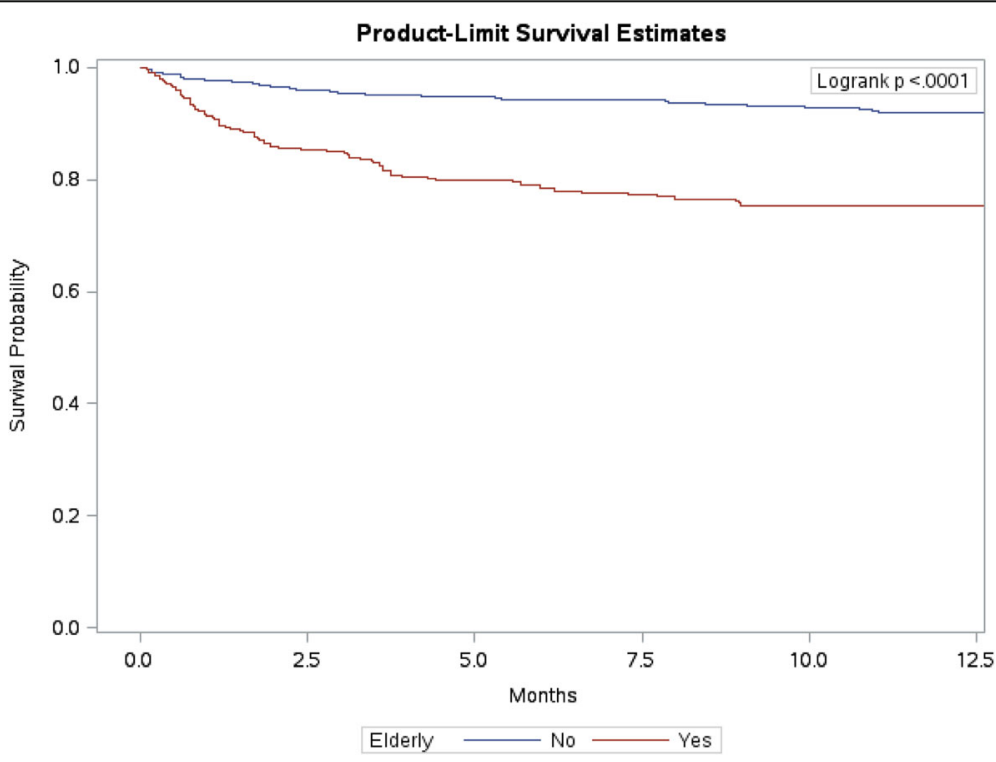

Fig. 1 Survival probability stratified by age groups 


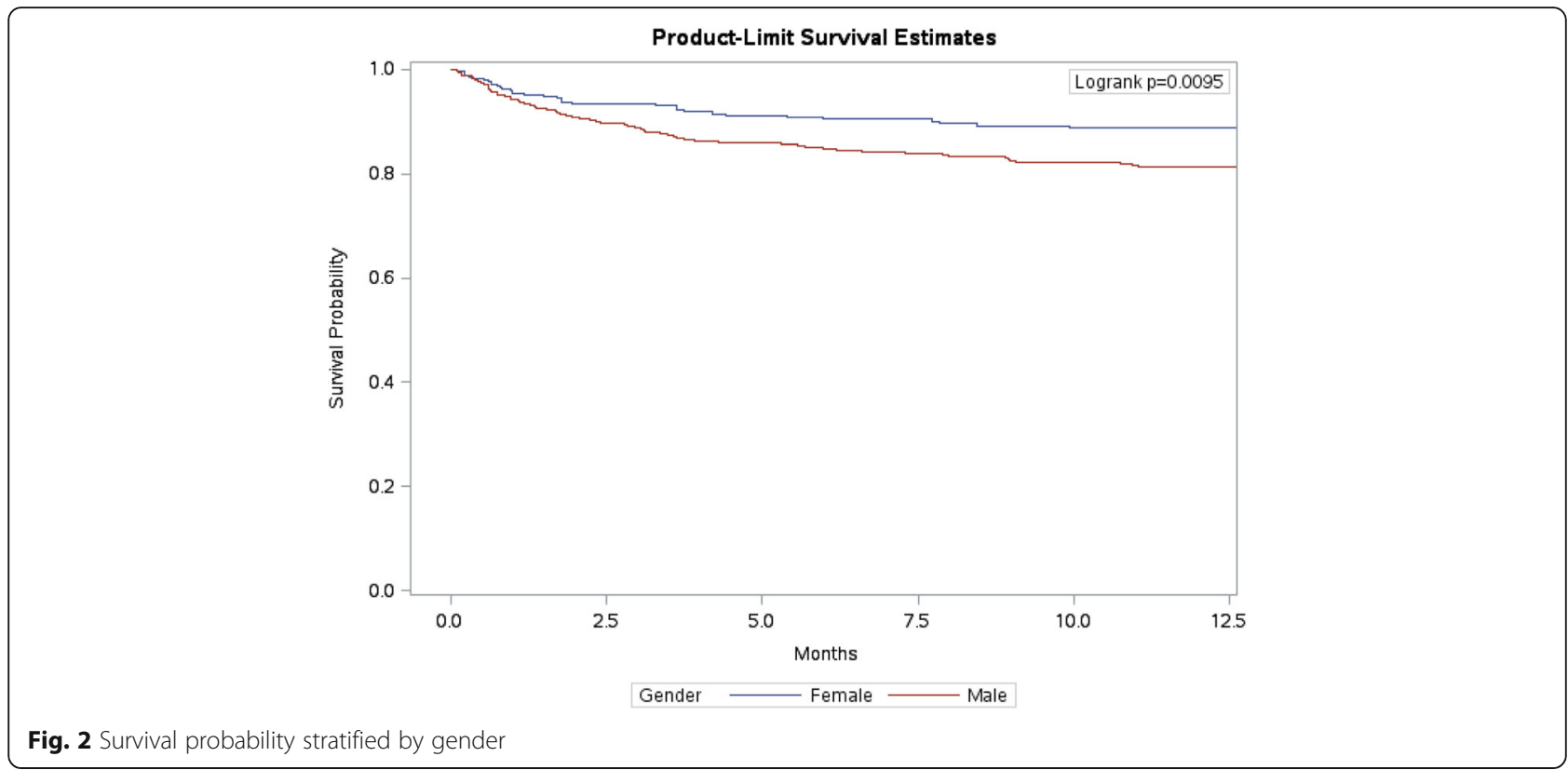

(aHR: 1.898 [95\% CI: $1.005-3.582, P=0.048]$, aHR: 2.346 [95\% CI: $1.313-4.192, P=0.004]$, aHR: 3.292 [95\% CI: 1.804-6.006, $P=0.001]$ ), respectively.

\section{Discussion}

We found an overall mortality rate of 22 per 1000 PY, with higher mortality rates among the elderly, males, and patients with PTB. Also, we found higher mortality hazard among patients with respiratory comorbidities, other type of comorbidities, and cancer. A retrospective cohort study found a mortality rate of 8.79 per 1000 PY [21]. The difference between these findings could be explained by the underlying differences in populations under investigation, trends of TB, and patterns of TB spread among the population. Many other studies have investigated TB mortality [2, 22-25], but, unfortunately, direct comparison

Table 4 Factors associated with 5-year mortality rate among TB cases

\begin{tabular}{|c|c|c|c|c|c|c|c|c|}
\hline \multirow[t]{3}{*}{ Variables } & \multirow{3}{*}{$P$} & \multirow{3}{*}{$\begin{array}{l}\text { Univariate } \\
\mathrm{HR}\end{array}$} & & & \multicolumn{4}{|c|}{ Multivariate } \\
\hline & & & \multicolumn{2}{|l|}{$95 \% \mathrm{Cl}$} & \multirow[t]{2}{*}{$P$} & \multirow[t]{2}{*}{$\mathrm{aHR}$} & \multicolumn{2}{|l|}{$95 \% \mathrm{Cl}$} \\
\hline & & & Lower & Upper & & & Lower & Upper \\
\hline Age & $0.001^{*}$ & 1.031 & 1.021 & 1.042 & $0.002^{*}$ & 1.024 & 1.009 & 1.039 \\
\hline Male & $0.010^{*}$ & 1.697 & 1.132 & 2.542 & $0.010^{*}$ & 2.014 & 1.186 & 3.418 \\
\hline Saudi & 0.296 & 0.681 & 0.332 & 1.4 & 0.282 & 0.599 & 0.235 & 1.525 \\
\hline Obesity & 0.816 & 1.076 & 0.582 & 1.989 & 0.677 & 0.87 & 0.452 & 1.676 \\
\hline Smoke & 0.579 & 0.776 & 0.316 & 1.904 & 0.912 & 1.055 & 0.41 & 2.712 \\
\hline \multicolumn{9}{|l|}{ Clinical features } \\
\hline General & 0.092 & 1.545 & 0.932 & 2.56 & $0.049^{*}$ & 1.913 & 1.004 & 3.644 \\
\hline Systemic & 0.248 & 0.802 & 0.552 & 1.166 & 0.234 & 0.747 & 0.462 & 1.208 \\
\hline Respiratory & 0.372 & 0.843 & 0.58 & 1.225 & 0.796 & 1.074 & 0.627 & 1.837 \\
\hline Cavitations & 0.093 & 0.558 & 0.282 & 1.103 & 0.064 & 0.441 & 0.186 & 1.049 \\
\hline Site of TB & 0.396 & 1.176 & 0.809 & 1.71 & 0.744 & 1.093 & 0.641 & 1.861 \\
\hline \multicolumn{9}{|l|}{ Comorbidities } \\
\hline Respiratory & $0.023^{*}$ & 1.823 & 1.087 & 3.057 & $0.048^{*}$ & 1.898 & 1.005 & 3.582 \\
\hline Other & $0.001^{*}$ & 2.377 & 1.569 & 3.602 & $0.004^{*}$ & 2.346 & 1.313 & 4.192 \\
\hline Cancer & $0.001^{*}$ & 3.274 & 1.995 & 5.373 & $0.001^{*}$ & 3.292 & 1.804 & 6.006 \\
\hline Immunocompromised & 0.842 & 1.076 & 0.524 & 2.209 & 0.319 & 0.589 & 0.208 & 1.668 \\
\hline
\end{tabular}

*Wald chi-square test is significant $\mathrm{a}=0.05$. $\mathrm{HR}$, hazard ratio; aHR, adjusted hazard ratio 
between our results and their results cannot be made due to different estimates used to assess mortality among these populations. Most of the studies used case fatality rates (CFRs) and standardized death ratio (SMR), while in our study we used mortality rate per PY.

Our study demonstrated a higher mortality rate among the elderly. We found a positive association between age and the hazard of mortality, which is consistent with several studies [2, 26, 27], the first of which is a Saudi cohort reporting a positive correlation between age and mortality among TB patients as well. The highest mortality rate among age groups was in the elderly $(\geq 65$ years) [2]. The second study evaluated mortality in a large TB treatment trial conducted in the United States and Canada, which found a similar hazard of mortality with age [26]. The last study, which included Taiwanese TB patients, also reported a higher hazard of mortality in age group of $\geq 75$ [27]. Males are more prone to death from TB. They have a double mortality rate and $90 \%$ higher hazard compared to females, which agrees with the results of previous studies [2, 22, 23, 28, 29]. An analysis of European surveillance data in 2008 showed a $50 \%$ higher risk of death among male TB patients [30]. The positive association between males and death has also been reported in many other studies [24, 25, 31]. The highest mortality rate we found was among PTB patients. Another study of 3451 patients also reported a higher mortality rate among PTB patients compared to extra-pulmonary [32].

The hazard of death was $89.9 \%$ and two times higher among patients with pulmonary and other comorbidities. We did not find many studies investigating the differences between the effect of these two comorbidities on TB mortality, rather they studied the effect of the presence or absence of chronic diseases in general without specification. One study reported a three times higher hazard of death among patients with at least one comorbidity [28]. Cancer patients had the second highest mortality rate; the hazard of death was four times higher among cancer patients with $\mathrm{TB}$, and similar findings were reported by several researchers. A higher risk of TB patient death was associated with malignancy in several studies $[26,33]$.

This is a retrospective cohort study that has several limitations regarding data quality. It is a single-center experience with a small number of identified resistant cases and no MDR-TB reporting system to ensure accuracy of cases identifications. We investigated TB mortality in a tertiary care hospital setting, which tends to have patients with more advanced TB disease condition and co-multi-morbidities. Data about human immunodeficiency virus (HIV) infection was unavailable, although we collected data about immunosuppression in general. Socioeconomic data were also unavailable. Further multicenter studies are needed to accurately estimate the mortality rate of resistant $\mathrm{TB}$ in this population and explore other potential risk factors associated with $\mathrm{TB}$ mortality, including human immunodeficiency virus (HIV) infection and socioeconomic factors, such as income.

\section{Conclusions}

Mortality rate among TB patients was found 22 per 1000 PY in our center. TB was associated with high mortality rate among males, the elderly, and patients with cancer, respiratory, and other comorbidities. Future clinical practice should include establishing efficient TB diagnostic programs and continued hazard assessments in TB patients' treatment options. Extra caution must be taken while treating the elderly and patients with one or more comorbidities. Additionally, clinicians should be alert to any sign of treatment failure.

\section{Abbreviations \\ AFB: Acid-Fast Bacilli; aHR: Adjusted Hazard Ratio; BMI: Body Mass Index; CFRs: Case Fatality Rates; CPH: Cox Proportional Hazards; EPTB: Extra Pulmonary Tuberculosis; HR: Hazard Ratio; MDR-TB: Multidrug-Resistant Tuberculosis; PTB: Pulmonary Tuberculosis; PY: Person-Years; RR- TB: Rifampicin-Resistant Tuberculosis; SMR: Standardized Death Ratio; TB: Tuberculosis; WHO: The World Health Organization; XDR-TB: Extensively Drug-Resistant Tuberculosis}

\section{Acknowledgements}

Not applicable.

Funding

This study was sponsored by King Abdulaziz City for Science and Technology (KACST). KACST approved and supervised the study. The authors would like to express their gratitude and appreciation to KACST for providing the research grant for this study (grant number 1-17-03-025-0001).

\section{Availability of data and materials}

The datasets generated and analyzed during the current study are not publicly available so as to protect participant information confidentiality. They are available, however, from the corresponding author upon reasonable request.

\section{Authors' contributions}

RA designed the study, collected the data, performed the statistical analysis, interpreted the results, and drafted the manuscript. AA and HA participated in the study design, statistical analysis, and helped to draft the manuscript. All authors read and approved the final manuscript.

\section{Ethics approval and consent to participate}

This study was conducted with ethical approval from the Ethical Committee of King Abdullah International Medical Research Center (KAIMRC), and the permission required to access the raw data was provided by KAIMRC. The need for participants consent was waived by the IRB, as the research did not involve any procedures or represent any harm to participants. Further, to avoid any potential breach of confidentiality, necessary participant identifiers were removed from data files and were stored in a physically separated and secured location.

\section{Consent for publication}

Not applicable.

Competing interests

The authors declare that they have no competing interests. 


\section{Publisher's Note}

Springer Nature remains neutral with regard to jurisdictional claims in published maps and institutional affiliations.

\section{Author details}

${ }^{1}$ Saudi Food and Drug Authority, Riyadh, Saudi Arabia. ${ }^{2}$ King Saud bin Abdulaziz University for Health Sciences, Riyadh, Saudi Arabia. ${ }^{3}$ King Abdullah International Medical Research Center, Riyadh, Saudi Arabia. ${ }^{4}$ Ministry of the National Guard-Health Affairs, Riyadh, Saudi Arabia.

Received: 22 February 2018 Accepted: 2 May 2019

Published online: 16 May 2019

\section{References}

1. Al-Orainey I, Alhedaithy MA, Alanazi AR, Barry MA, Almajid FM. Tuberculosis incidence trends in Saudi Arabia over 20 years: 1991-2010. Ann Thorac Med. 2013:8(3):148.

2. Abouzeid MS, ab Rafaat F, Memishb ZA. Mortality among tuberculosis patients in Saudi Arabia (2001-2010). Ann Saudi Med. 2013;33(3):247.

3. World Health Organization (WHO). Tuberculosis fact sheet. http://www.who. int/mediacentre/factsheets/fs104/en/ [Accessed October 2016].

4. Centers for Disease Control and Prevention (CDC). Multidrug resistant tuberculosis (MDR TB) fact sheet. [Accessed may 11, 2016].

5. Kliiman K, Altraja A. Predictors and mortality associated with treatmen default in pulmonary tuberculosis. Int J Tuberc Lung Dis. 2010;14(4):454-63.

6. Franke MF, Appleton SC, Bayona J, Arteaga F, Palacios E, Llaro K, Shin SS, Becerra MC, Murray MB, Mitnick CD. Risk factors and mortality associated with default from multidrug-resistant tuberculosis treatment. Clin Infect Dis. 2008:46(12):1844-51

7. Cox H, Kebede Y, Allamuratova S, Ismailov G, Davletmuratova Z, Byrnes G, Stone C, Niemann S, Rüsch-Gerdes S, Blok L, Doshetov D. Tuberculosis recurrence and mortality after successful treatment: impact of drug resistance. PLoS Med. 2006;3(10):e384.

8. Podewils L, Holtz T, Riekstina V, Skripconoka V, Zarovska E, Kirvelaite G, Kreigere $\mathrm{E}$, Leimane $\mathrm{V}$. Impact of malnutrition on clinical presentation, clinical course, and mortality in MDR-TB patients. Epidemiol Infect. 2011; 139(01):113-20.

9. Gandhi NR, Andrews JR, Brust JC, Montreuil R, Weissman D, Heo M, Moll AP, Friedland GH, Shah NS. Risk factors for mortality among MDRand XDR-TB patients in a high HIV prevalence setting. Int J Tuberc Lung Dis. 2012;16(1):90-7.

10. Kvasnovsky CL, Cegielski JP, Erasmus R, Siwisa NO, Thomas K, van der Walt ML. Extensively drug-resistant TB in eastern cape, South Africa: high mortality in HIV-negative and HIV-positive patients. J Acquir Immune Defic Syndr. 2011;57(2):146-52.

11. World Health Organization. Global tuberculosis report 2016. World Health Organization; 2016. http://www.who.int/tb/publications/global_report/en/ [Accessed October 2016].

12. The economic impacts of tuberculosis. Geneva, World Health Organization, 2000.

13. Hansel NN, Wu AW, Chang B, Diette GB. Quality of life in tuberculosis: patient and provider perspectives. Qual Life Res. 2004;13(3):639-52.

14. World Health Organization (WHO). Tuberculosis country profiles: Saudi Arabia 2016. https://www.who.int/gho/countries/sau/country_profiles/en/ [Accessed October 2016].

15. Kordy F, Al-Thawadi S, Alrajhi A. Drug resistance patterns of mycobacterium tuberculosis in Riyadh, Saudi Arabia. Int J Tuberc Lung Dis. 2004;8(8):1007-11.

16. Al-Hajoj S, Zozio T, Al-Rabiah F, et al. First insight into the population structure of mycobacterium tuberculosis in Saudi Arabia. J Clin Microbiol. 2007:45(8):2467-73.

17. Ellis ME, Al-Hajjar S, Bokhari H, Qadri SM. High proportion of multi-drug resistant mycobacterium tuberculosis in Saudi Arabia. Scand I Infect Dis. 1996:28(6):591-5

18. Chaudhry L, Rambhala N, Al-Shammri A, Al-Tawfiq J. Patterns of antituberculous drug resistance in eastern Saudi Arabia: a 7 -year surveillance study from 1/2003 to 6/2010. J Epidemiol Glob Health. 2012;2:57-60.

19. Lewinsohn DM, Leonard MK, LoBue PA, Cohn DL, Daley CL, Desmond E, Keane J, Lewinsohn DA, Loeffler AM, Mazurek GH, O'Brien RJ. Official American Thoracic Society/Infectious Diseases Society of America/Centers for Disease Control and Prevention clinical practice guidelines: diagnosis of tuberculosis in adults and children. Clin Infect Dis. 2017;64(2):e1-33.
20. IBM Corp. Released 2012. IBM SPSS Statistics for Macintosh, Version 21.0 Armonk, NY: IBM Corp.

21. Miller TL, Wilson FA, Pang JW, Beavers S, Hoger S, Sharnprapai S, Pagaoa M, Katz DJ, Weis SE. Mortality hazard and survival after tuberculosis treatment. Am J Public Health. 2015;105(5):930-7.

22. Mathew TA, Ovsyanikova TN, Shin SS, Gelmanova I, Balbuena DA, Atwood S, Peremitin GG, Strelis AK, Murray MB. Causes of death during tuberculosis treatment in Tomsk oblast, Russia. Int J Tuberc Lung Dis. 2006;10(8):857-63.

23. Kulkarni MS, Vaz FS, Motghare DD, Ferreira AM. Trends in tuberuclosis mortality rates in Goa (1991-2001). NTI Bulletin. 2007:43(1\&2):9-13.

24. Dale K, Tay E, Trevan P, Denholm JT. Mortality among tuberculosis cases in Victoria, 2002-2013: case fatality and factors associated with death. Int J Tuberc Lung Dis. 2016;20(4):515-23.

25. Borgdorff MW, Veen J, Kalisvaart NA, Nagelkerke N. Mortality among tuberculosis patients in the Netherlands in the period 1993-1995. Eur Respir J. 1998;11(4):816-20

26. Sterling TR, Zhao Z, Khan A, Chaisson RE, Schluger N, Mangura B, Weiner M, Vernon A. Tuberculosis trials consortium. Mortality in a large tuberculosis treatment trial: modifiable and non-modifiable risk factors. Int J Tuberc Lung Dis. 2006;10(5):542-9.

27. Yen YF, Feng JY, Pan SW, Chuang PH, Su VF, Su WJ. Determinants of mortality in elderly patients with tuberculosis: a population-based follow-up study. Epidemiol Infect. 2017;145(7):1374-81.

28. Low S, Ang LW, Cutter J, James L, Chee CB, Wang YT, Chew SK. Mortality among tuberculosis patients on treatment in Singapore. Int J Tuberc Lung Dis. 2009:13(3):328-34

29. Ochoa EG, Oliva GE, Gutiérrez SB, González AP, Pérez LA. Tuberculosis mortality trends in Cuba, 1998 to 2007. MEDICC review. 2009;11(1):42-7.

30. Lefebvre N, Falzon D. Risk factors for death among tuberculosis cases: analysis of European surveillance data. Eur Respir J. 2008;31(6):1256-60.

31. Vasankari T, Holmström P, Ollgren J, Liippo K, Kokki M, Ruutu P. Risk factors for poor tuberculosis treatment outcome in Finland: a cohort study. BMC Public Health. 2007:7(1):291.

32. Horne DJ, Hubbard R, Narita M, Exarchos A, Park DR, Goss CH. Factors associated with mortality in patients with tuberculosis. BMC Infect Dis. 2010; 10(1):258.

33. Balabanova $Y$, Ignatyeva $O$, Fiebig L, Riekstina V Danilovits $M$, Jaama $K$, Davidaviciene E, Radiulyte B, Popa CM, Nikolayevskyy V, Drobniewski F. Survival of patients with multidrug-resistant TB in Eastern Europe: what makes a difference?. Thorax. 2016;71(9):854-61.

\section{Ready to submit your research? Choose BMC and benefit from:}

- fast, convenient online submission

- thorough peer review by experienced researchers in your field

- rapid publication on acceptance

- support for research data, including large and complex data types

- gold Open Access which fosters wider collaboration and increased citations

- maximum visibility for your research: over $100 \mathrm{M}$ website views per year

At $\mathrm{BMC}$, research is always in progress.

Learn more biomedcentral.com/submission 